\title{
Measurement of optic nerve sheath diameter by ultrasound: a means of detecting acute raised intracranial pressure in hydrocephalus
}

\author{
W D Newman, A S Hollman, G N Dutton, R Carachi
}

Br J Ophthalmol 2002;86:1 109-1 113

Aim: To evaluate the utility of measuring the optic nerve sheath diameter in children with shunted hydrocephalus, suspected of having raised intracranial pressure.

Methods: 23 children with shunted hydrocephalus were examined, six had well controlled ICP, 17 however manifested symptoms suggestive of intracranial hypertension. A clinical history was taken from all patients and their parents or carers. The shunt valve was examined clinically, and signs of raised intracranial pressure were sought. Ultrasound examination was performed in both eyes to measure the optic nerve sheath diameters $3 \mathrm{~mm}$ behind the globe. These measurements were compared with control data obtained from 102 children who attended the radiology department for unrelated renal ultrasound examination.

Results: Control data suggested that the upper limit of normal for optic nerve sheath diameter is $4.5 \mathrm{~mm}$ (measured $3 \mathrm{~mm}$ behind the globe) in patients over 1 year of age, and $4.0 \mathrm{~mm}$ in children less than 1 year of age. Those patients with functioning ventriculoperitoneal shunts had a mean optic nerve sheath diameter of 2.9 (SD 0.5) mm; those with raised intracranial pressure had a mean optic nerve sheath diameter of $5.6(0.6) \mathrm{mm}(\mathrm{p}<0.0001)$. These results confirm that optic nerve sheath diameters in excess of the control data are strongly suggestive of raised intracranial pressure.

Conclusion: The evaluation of the optic nerve sheath diameter is a simple non-invasive procedure, which is a potentially useful tool in the assessment and monitoring of children with hydrocephalus suspected of having raised intracranial pressure.

\section{PATIENTS AND METHODS}

Children with shunted hydrocephalus aged between 10 days and 16 years were recruited between January 1997 and January 1999. The results obtained were compared with age matched normal control data collected by the same investigating group between 1997 and 1998 and published in $1999 .{ }^{3}$

All the children underwent ultrasound examination by a radiologist. The diameter of the optic nerve sheath $3 \mathrm{~mm}$ behind the posterior scleral surface was measured using an Acuson 128XP 10 system with a sector $7 \mathrm{MHZ}$ phased array probe (Acuson paediatric V7 transducer). To reduce anxiety levels and have the cooperation required, the examinations took place in a dimly lit room with background music, with the patients supine with a comforter if appropriate. The probe was applied with coupling gel to the closed eyelid. This method was used to reduce the cooperation required from the patient. Three measurements were taken for each optic nerve with standardised instrument settings (departmental proto$\mathrm{col}$ ) using the digital cursor and measurement software of the

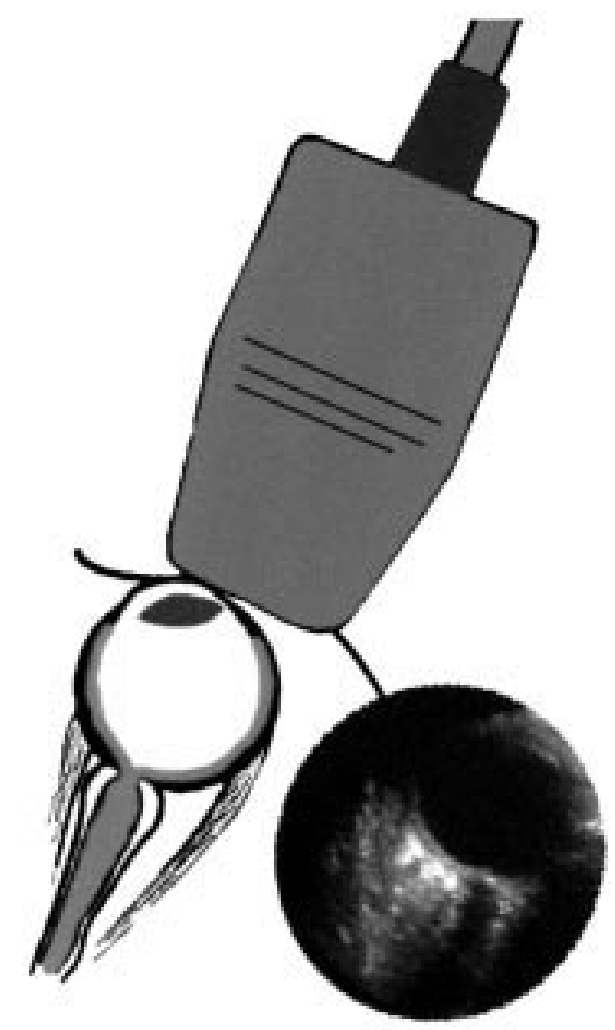

Figure 1 The technique of ocular ultrasound and the image with the cursors set at $3 \mathrm{~mm}$ behind the globe to measure the optic nerve sheath diameter 
Table 1 Clinical details of the patients in groups 2, 3, and 4

\begin{tabular}{|c|c|c|c|c|c|c|c|c|c|}
\hline \multirow[b]{2}{*}{ Group } & \multirow{2}{*}{$\begin{array}{l}\text { Patient } \\
\text { No }\end{array}$} & \multirow[b]{2}{*}{ Sex } & \multirow[b]{2}{*}{ Age } & \multirow[b]{2}{*}{ Diagnosis } & \multirow[b]{2}{*}{ Presenting symptom/sign } & \multirow{2}{*}{$\begin{array}{l}\text { Optic disc } \\
\text { appearances }\end{array}$} & \multicolumn{2}{|c|}{$\begin{array}{l}\text { Optic nerve sheath } \\
\text { diameter }(\mathrm{mm})\end{array}$} & \multirow{2}{*}{ Comment } \\
\hline & & & & & & & Right & Left & \\
\hline \multirow[t]{6}{*}{ Group 2} & 1 & $\mathrm{~F}$ & 13 years & Primary hydrocephalus & None, routine review & & 4.1 & 3.5 & \\
\hline & 2 & M & 6 years & Primary hydrocephalus & None, routine review & & 3.0 & 3.0 & \\
\hline & 3 & M & 18 months & Spina bifida and hydrocephalus & None, routine review & Normal & 2.5 & 2.9 & \\
\hline & 4 & M & 6 years & Post haemorrhagic hydrocephalus & None, routine review & & 3.0 & 2.5 & \\
\hline & 5 & $\mathrm{~F}$ & 13 years & Primary hydrocephalus & None, routine review & Normal & 3.1 & 3.5 & \\
\hline & 6 & M & 10 days & $\begin{array}{l}\text { Thoraco-lumbar myelomenigocele and } \\
\text { hydrocephalus }\end{array}$ & None, routine review & & 1.9 & 2.6 & \\
\hline \multirow[t]{5}{*}{ Group 3} & 7 & $\mathrm{~F}$ & 6 years & Post haemorrhagic hydrocephalus & Increasing stammer and irritability & Cupped discs & 3.4 & 3.4 & Resolved spontaneously \\
\hline & 8 & & 14 months & Post haemorrhagic hydrocephalus & Screaming and irritability & & 2.6 & 2.6 & Resolved spontaneously \\
\hline & 9 & M & 4 years & Holoprosencephaly and hydrocephalus & Nausea, vomiting, and drowsiness & Normal & 2.8 & 2.8 & Resolved spontaneously \\
\hline & 10 & $\mathrm{~F}$ & 10 years & Post haemorrhagic hydrocephalus & Irritable, intermittent headaches, vomited once & Normal & 3.3 & 3.8 & Resolved spontaneously \\
\hline & 11 & $\mathrm{~F}$ & 3 years & Primary hydrocephalus & Chronic headaches & Swollen discs & 3.0 & 3.0 & Over draining shunt, slit ventricle syndrome \\
\hline \multirow[t]{12}{*}{ Group 4} & 12 & $\mathrm{~F}$ & 18 months & Communicating hydrocephalus & Cannot fill reservoir & Normal & 5.6 & 5.6 & $\begin{array}{l}\mathrm{CT} \text { consistent with raised ICP shunt revised Raised } \\
\text { ICP found at shunt revision }\end{array}$ \\
\hline & 13 & M & 10 days & $\begin{array}{l}\text { Anteroparietal porencephaly, Post } \\
\text { meningitic hydrocephalus }\end{array}$ & Seizures & & 5.9 & 5.9 & $\begin{array}{l}\text { Cranial ultrasound increased ventricular size shunt } \\
\text { revised }\end{array}$ \\
\hline & 14 & $\mathrm{~F}$ & 3 & Post haemorrhagic hydrocephalus & Vomiting and irritability Leff VIn paresis & Swollen discs & 6.5 & 5.8 & Shunt revised raised ICP found at shunt revision \\
\hline & 15 & M & 84 days & Post haemorrhagic hydrocephalus & Increasing head circumference Photophobia and vomiting & & 6.5 & 6.7 & $\begin{array}{l}\text { Cranial ultrasound increased ventricular size raised } \\
\text { ICP- } 32 \mathrm{~cm} \mathrm{H} \mathrm{H}_{2} \mathrm{O} \text { shunt revised }\end{array}$ \\
\hline & 16 & M & 2 years & Post haemorrhagic hydrocephalus & Drowsy and vomiting & Normal & 6.3 & 5.5 & Shunt revised \\
\hline & 17 & $\mathrm{~F}$ & 7 years & Hydrocephalus & Vomiting, headaches & & 5.6 & 6.6 & Shunt revised raised ICP at shunt revision \\
\hline & 18 & M & 6 & Myelomeningocele with hydrocephalus & Unwell with headaches & Optic atrophy & 5.5 & 5.7 & Shunt revised raised ICP at shunt revision \\
\hline & 19 & M & $2 / 12$ & Primary hydrocephalus & Bulging fontanels & Normal & 4.7 & 4.6 & $\begin{array}{l}\text { Cranial ultrasound, increased ventricular size shunt } \\
\text { revised }\end{array}$ \\
\hline & $20(1)$ & M & 16 & Spina bifida & Headache, nausea, reduced conscious level & Normal & 5.3 & 5.0 & $\mathrm{CT}$ consistent with raised ICP shunt revised \\
\hline & $21(2)$ & $\mathrm{F}$ & $1 / 12$ & Post haemorrhagic hydrocephalus & Vomiting, irritable and reduced conscious level & & 5.0 & 5.0 & Shunt blocked shunt revised \\
\hline & $22(3)$ & $\mathrm{F}$ & 1 year & Cervical meningocele & Unresponsive, irritable vomiting swollen discs & Swollen discs & 5.7 & 4.5 & CSF pressure $>40 \mathrm{~cm} \mathrm{H}_{2} \mathrm{O}$ shunt revised \\
\hline & $23(4)$ & $\mathrm{F}$ & 3 months & Post meningitic hydrocephalus & Reduced level of consciousness & & 5.3 & 4.3 & CSF pressure $25 \mathrm{~cm} \mathrm{H}_{2} \mathrm{O}$ shunt revised \\
\hline
\end{tabular}




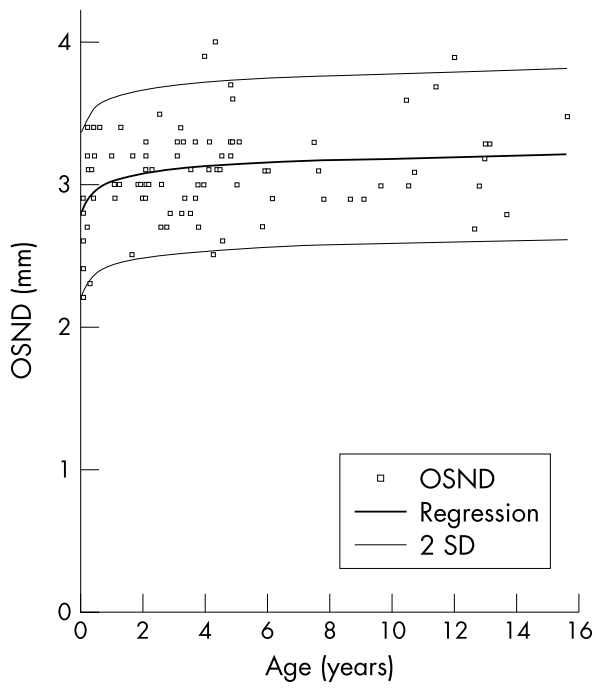

Figure 2 Optic nerve sheath diameters of those in group 1 plotted in relation to age. Logarithmic regression line of ONSD with age. Logarithmic regression ( \pm 2 SD) illustrating $95 \%$ confidence interval. (Reproduced with permission of Harcourt Health Services and Ballantyne et al. ${ }^{3}$ )

ultrasound machine (Fig 1). The examining radiologist was aware of the clinical history and preliminary clinical diagnosis. The films were subsequently independently reviewed and the mean optic nerve sheath diameter (ONSD) determined by the lead investigator $(\mathrm{AH})$ who was masked to all the clinical details.

A detailed clinical history was documented from the patients or witnesses, and the children were examined for clinical evidence of raised ICP and shunt dysfunction; where possible the shunt valve was examined. The paediatric physicians and surgeons decided whether imaging of the shunt was required. Where appropriate neurological imaging was carried out. Thirteen of the patients had their optic discs examined by a member of the paediatric ophthalmology team.

On the basis of the outcome of their clinical condition and whether surgical intervention was required the children were ultimately placed into one of four groups:

Group 1 comprised 102 normal children attending the radiology department for renal ultrasound examination following a urinary tract infection ${ }^{3}$

Group 2 comprised six children with shunted hydrocephalus attending the outpatient department for routine review

Group 3 comprised five children who had initial symptoms suggestive of raised ICP but whose symptoms abated spontaneously

Group 4 was made up of 12 children with symptoms suggestive of raised ICP in whom it was subsequently confirmed that ICP was raised and required appropriate intervention. Four children in this group with recurrent symptomatology were followed up longitudinally for 2-12 months.

The clinical details of groups 2,3 , and 4 are summarised in Table 1.

The optic nerve sheath diameter and clinical outcome data were analysed by a single investigator (WN) who had not been involved in the patients' clinical care or the measurement of the optic nerve sheath diameter.

\section{RESULTS}

Figure 2 shows the nomogram of the normal development of optic nerve sheath diameter in the 102 control children ${ }^{3}$ in group 1 . The range was $2.1-4.3 \mathrm{~mm}$ with a mean of 3.1 (SD $0.36) \mathrm{mm}$. Logarithmic regression analysis demonstrated a relation between increasing age and increasing optic nerve sheath diameter $\left(r^{2}=0.48\right)$, with the greatest increase occurring in the first year of life. Under 1 year of age the mean ONSD was $2.9 \mathrm{~mm}$, range $2.2-3.4 \mathrm{~mm}$ (SD 0.4), and 1 year or over the mean ONSD was $3.1 \mathrm{~mm}$ range, $2.3-4.0 \mathrm{~mm}$, SD 0.3 $(p=0.01)$. Measurement of the variability in this group demonstrated that using the mean of the three values was, on average, within $0.08 \mathrm{~mm}$ of the true mean. ${ }^{3}$ For the purposes of the study the upper limit of normal was defined as $4.0 \mathrm{~mm}$ for those under 1 year of age and $4.5 \mathrm{~mm}$ for older children.

Table 2 shows the measurements obtained for all groups. Group 2 comprised six children with shunted hydrocephalus who were clinically normotensive and the range and mean values for the ONSD accorded with those of the control population. Group 3 comprised five children who manifested symptoms suggestive of raised ICP. These included irritability, tiredness, nausea, and headache. However, in all of these children the symptoms abated within 24 hours and in each case the optic nerve sheath diameters were less than $4.5 \mathrm{~mm}$.

The 12 children in group 4 had been admitted to hospital with the same range of symptoms as those in group 3. However, their symptoms persisted or became worse. All of these children had optic nerve sheath diameters of $4.5 \mathrm{~mm}$ or greater. In each case, confirmatory tests as identified in Table 2 revealed evidence of raised ICP. In 11 cases, the shunts were revised and in one, medical treatment (isosorbide) was given.

Four patients with recurrent ventriculoperitoneal shunt problems underwent serial optic nerve sheath diameter measurements over a period ranging between 2 and 13 months. Table 3 summarises the results obtained. Measurements taken at the time of raised ICP (necessitating shunt revision) were compared with those taken during the intervening period. Figure 3 illustrates these results graphically. In every case, the optic nerve sheath diameters were within the normal range while the children were asymptomatic, but were all greater than the normal range when the ICP was elevated and symptoms were present.

\section{DISCUSSION}

The optic nerve sheath is anatomically continuous with the dura mater, and has a trabeculated arachnoid space through

\begin{tabular}{|c|c|c|c|c|c|}
\hline \multirow[b]{2}{*}{ Group } & \multirow[b]{2}{*}{ Number } & \multirow[b]{2}{*}{ Clinical features } & \multicolumn{3}{|l|}{ ONSD } \\
\hline & & & Range & Mean & SD \\
\hline 1 & 102 & Normal & $2.1-4.3 \mathrm{~mm}$ & $3.1 \mathrm{~mm}$ & 0.36 \\
\hline 2 & 6 & Hydrocephalus, normotensive & $2.1-3.6 \mathrm{~mm}$ & $2.9 \mathrm{~mm}$ & 0.5 \\
\hline 3 & 5 & $\begin{array}{l}\text { Hydrocephalus, symptoms of suggestive of raised } \\
\text { ICP, not requiring intervention }\end{array}$ & $2.6-3.8 \mathrm{~mm}$ & $3.1 \mathrm{~mm}$ & 0.4 \\
\hline 4 & 12 & $\begin{array}{l}\text { Hydrocephalus, symptoms suggestive of raised } \\
\text { ICP, requiring intervention }\end{array}$ & $4.5-7.0 \mathrm{~mm}$ & $5.9 \mathrm{~mm}$ & 0.6 \\
\hline
\end{tabular}


Table 3 Optic nerve sheath diameters in four patients who were observed longitudinally comparing the values obtained when the shunts were occluded and when they were patent

\begin{tabular}{llllllll}
\hline & \multicolumn{3}{l}{ ONSD at time of shunt revision } & & \multicolumn{3}{l}{ ONSD during intervening period } \\
\cline { 2 - 5 } \cline { 6 - 8 } Patient & Range & Mean & SD & & Range & Mean & SD \\
\hline 1 & $5.0-8.0 \mathrm{~mm}$ & $6.2 \mathrm{~mm}$ & 1.1 & & $2.5-4.0 \mathrm{~mm}$ & $3.3 \mathrm{~mm}$ & 0.9 \\
2 & $4.4-5.6 \mathrm{~mm}$ & $5.0 \mathrm{~mm}$ & 0.3 & & $2.2-4.3 \mathrm{~mm}$ & $3.1 \mathrm{~mm}$ & 0.6 \\
3 & $4.5-6.0 \mathrm{~mm}$ & $5.6 \mathrm{~mm}$ & 0.7 & & $3.5-4.4 \mathrm{~mm}$ & $3.9 \mathrm{~mm}$ & 0.4 \\
4 & $4.3-5.7 \mathrm{~mm}$ & $4.8 \mathrm{~mm}$ & 0.6 & & $2.5-4.6 \mathrm{~mm}$ & $3.4 \mathrm{~mm}$ & 0.5 \\
\hline
\end{tabular}

which cerebrospinal fluid slowly percolates. ${ }^{4}$ The substance of the nerve seen on ultrasound examination is homogeneous with low internal reflectivity compared with the high reflectivity of the nerve sheath: this was utilised by Ossoinig ${ }^{5}$ when he performed the first ultrasound measurement of the optic nerve using an A-scan technique, and subsequently described standardised A-scanning.

Using these echography techniques several groups have investigated the relation between the optic nerve sheath diameter as measured by A-scan and the ICP. Cennamo, ${ }^{6}$ Gangemi, ${ }^{7}$ and Tamburrelli ${ }^{8}$ each demonstrated a positive linear relation between these two variables in neurosurgical patients and in particular, an immediate change in ONSD with change in ICP.

Liu and Kahn, ${ }^{4}$ in a cadaver study, looked at the pressure gradient within the optic nerve sheath in relation to ICP and the anatomy of the optic nerve sheath. They noted that the trabeculations were most dense posteriorly being quite sparse anteriorly where the nerve sheath was thinnest and the most distensible. Although they did not measure the optic nerve sheath diameter they noted that " ... in all of the cadavers, the bulbous portion of the optic nerve was seen to bulge or inflate somewhat as the intracranial pressure was created, but there was no obvious change in appearance along the remaining nerve ...."
Hansen and co-workers in 1994 presented data using a transorbital B-scan approach for the measurement of ONSD. ${ }^{9}$ This approach allowed them to choose a distance behind the globe to consistently measure the nerve, something difficult to attain with A-scan techniques.

In 1996 Helmke and Hansen ${ }^{12}{ }^{10}$ went on to demonstrate, again in cadaver studies, that the ONSD increased by up to $60 \%$ at a distance of $3 \mathrm{~mm}$ behind the globe compared with only $35 \%$ at $10 \mathrm{~mm}$ thus confirming Liu and Kahn's observations. Furthermore, they went on to show that the optimal experimental scanning position was longitudinal (axial) where the least interobserver variability was found although there was no significant difference in measurement by lateral, axial, or transverse projection. This latter observation is of importance because transorbital B-scan ultrasonography looking along the optic nerve longitudinally relies on a poorer lateral resolution of the ultrasound pulse, rather than the high resolution perpendicular approach of a transverse scan. In their companion study of 39 children admitted to an intensive care unit; 24 were being treated for raised ICP, and the mean ONSD in these patients was $5.3 \mathrm{~mm}$ compared with the 12 patients admitted without raised ICP, in whom the mean ONSD was $3.1 \mathrm{~mm}$.

From the available data in the setting of paediatric practice the possible loss of ultrasound resolution in using this method

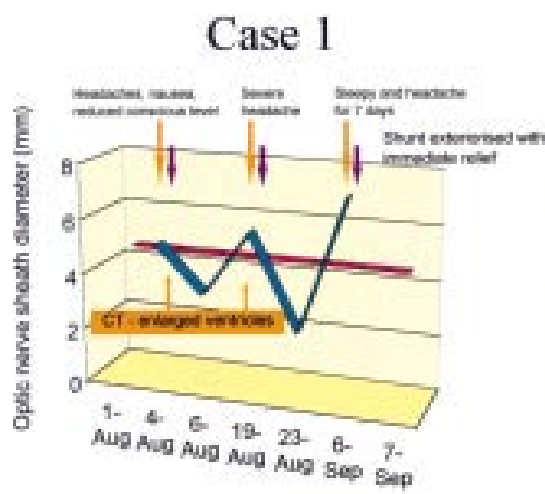

Case 3
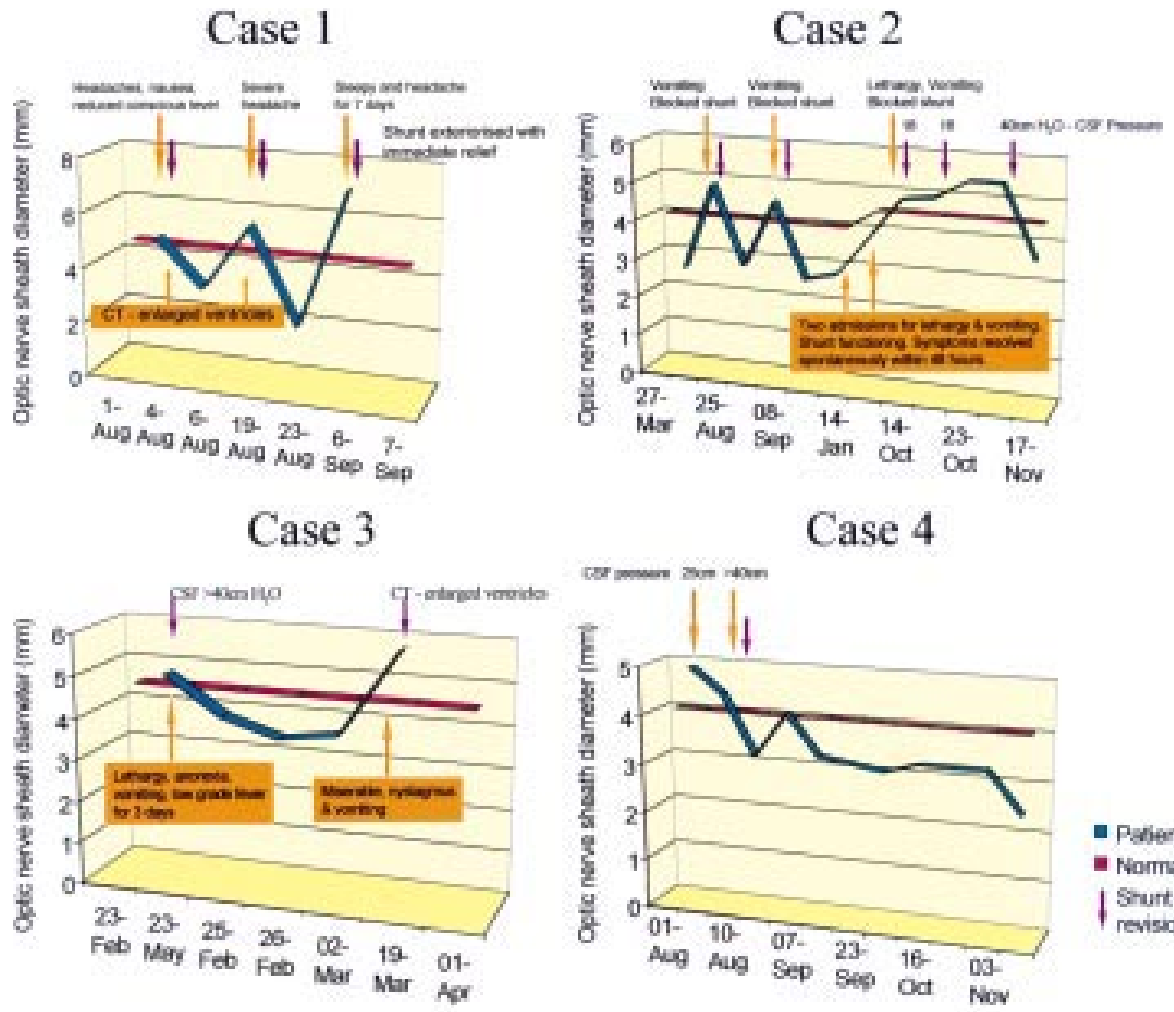
clinical status to the ultrasound findings in four children followed up longitudinally because of recurrent shunt dysfunction. 
of B-scan is offset by its ease of use and reduced level of cooperation required of the young patients when compared with standardised A-scanning techniques.

A position $3 \mathrm{~mm}$ behind the globe was chosen because the ultrasound contrast is greatest, the results are more reproducible, and anatomically the anterior nerve is most distensible. In the present study the average ONSD in the control group was $3.6 \mathrm{~mm}$ compared with $4.6 \mathrm{~mm}$ in the group with raised ICP. It was also noted that papilloedema was not found in the acute situation, but that increased ONSD may act as a marker for raised ICP before the development of papilloedema.

Acute intracranial hypertension in children can be difficult to diagnose because the symptoms are non-specific and direct measurement of intracranial pressure has the attendant risks of intracranial haemorrhage and infection. The advantages of ultrasound examination of the optic nerve head are that it is non-invasive, widely available, portable, rapidly performed, of relatively low cost, and it does not employ ionising radiation.

The results of the present study are encouraging. In the cases in which dilatation of the optic nerve sheath was identified, subsequent evolution of the symptomatology and further investigation confirmed raised ICP, but in all cases in which patients had suspicious symptoms but the optic nerve sheath diameter was normal, the symptoms abated; ICP measurement was not undertaken in this group as intervention was not deemed clinically necessary.

Our results indicate that measurements in excess of $4.0 \mathrm{~mm}$ under 1 year of age and $4.5 \mathrm{~mm}$ in older children suggest abnormal dilatation of the optic nerve sheath, and raised intracranial pressure should be suspected. However, as with all indirect indicators of intracranial pressure one should be cautious in interpreting negative findings. This study is too small to estimate the incidence of false negative findings.

Further studies are required to determine whether this clinical investigational approach should be adopted more widely, and to realise the potential of ultrasound examination of ONSD for the rapid diagnosis and monitoring of raised ICP.

\section{Authors' affiliations}

W D Newman, G N Dutton, Department of Ophthalmology, The Royal Hospital for Sick Children, Yorkhill, Glasgow G3 8SJ, UK

A S Hollman, Department of Radiology

R Carachi, Department of Surgery

Correspondence to: Dr W D Newman, Department of Ophthalmology, The Royal Hospital for Sick Children, Yorkhill, Glasgow G3 8SJ, UK: Bill_Newman@eyeweb.org.uk

Dr Anne S Hollman (consultant paediatric radiologist) died on 27 November 1999 shortly after the preparation of this manuscript.

This was presented at International Neuro-ophthalmology Society Meeting (INOS), Toronto, September 2000

Accepted for publication 17 April 2002

\section{REFERENCES}

1 Helmke H, Hansen HC. Fundamentals of transorbital sonographic evaluation of optic nerve sheath expansion under intracranial hypertension. I Experimental study. Paediatr Radiol 1996;26:701-5.

2 Helmke $\mathbf{H}$, Hansen HC. Fundamentals of transorbital sonographic evaluation of optic nerve sheath expansion under intracranial hypertension. II Patient study. Paedaitr Radiol 1996;26:706-10.

3 Ballantyne J, Hollman AS, Hamilton R, et al. Transorbital optic nerve sheath ultrasonography in normal children. Clin Radiol 1999;54:740-2.

4 Liu D, Kahn M. Measurement and relationship of subarachnoid pressure of the optic nerve to intracranial pressure in fresh cadavers. Am J Ophthalmol 1993;116:548-56.

5 Ossoinig KC. Standardised echography: basic principles, clinical applications and results. Int Ophthalmol Clin 1979;19:127-210.

6 Cennamo G, Gangemi M, Stella L. The correlation between endocranial pressure and optic nerve diameter: an ultrasonographic study. Ophthalmic Echography 1987;7:603-6.

7 Gangemi M, Cennamo G, Maiuri F, et al. Echographic measurement of the optic nerve in patients with intracranial hypertension. Neurochirugica 1987;30:53-5.

8 Tamburelli C, Aricle C, Mangiola A, et al. CSF dynamic parameters and changes of optic nerve diameters measured by standardised echography. Ophthalmic Echography 1993;13:101-9.

9 Hansen HC, Helmke K, Kunze K. Optic nerve sheath enlargement in acute intracranial hypertension. Neuro-ophthalmology 1994;14:345-54

10 Hansen HC, Helmke K. The subarachnoid space surrounding the optic nerves. An ultrasound study of the optic nerve sheath. Surg Radiol Anat $1996 ; 18: 323-8$.

\section{Video Reports (www.bjophthalmol.com)}

- Capsule staining and mature cataracts: a comparison of indocyanine green and trypan blue dyes. D F Chang

- Pearls for implanting the Staar toric IOL. D F Chang

- An intraocular steroid delivery system for cataract surgery. D F Chang

- Evaluation of leucocyte dynamics in mouse retinal circulation with scanning laser ophthalmoscopy. $H X_{U}$, A Manivannan, G Daniels, J Liversidge, P F Sharp, J V Forrester, I J Crane

- Dipetalonema reconditum in the human eye. T Huynh, J Thean, R Maini

- Surgical revision of leaking filtering blebs with an autologous conjunctival graft. K Taherian, A Azuara-Blanco

- Thixotropy: a novel explanation for the cause of lagophthalmos after peripheral facial nerve palsy. M Aramideh, J H T M Koelman, P P Devriese, F VanderWerf, J D Speelman 